\title{
Estimating hunting prevalence and reliance on wild meat in Cambodia's Eastern Plains
}

\author{
Harriet Ibbett, Aidan Keane, Andrew D. M. Dobson, Olly Griffin \\ Henry Travers and E.J. Milner-Gulland
}

\begin{abstract}
Hunting is a primary driver of biodiversity loss across South-east Asia. Within Cambodia, the use of wire snares to capture wildlife is a severe threat in protected areas but there have been few studies of the behaviour of hunters from local communities. Here, we combine the unmatched count technique with direct questioning to estimate the prevalence of hunting behaviours and wildlife consumption amongst 705 households living within Keo Seima Wildlife Sanctuary, Cambodia. We assessed respondents' knowledge of rules, and their perceptions of patrols responsible for enforcing rules. Estimates of hunting behaviour were variable: results from the unmatched count technique were inconclusive, and direct questioning revealed $9 \%$ of households hunted, and $20 \%$ set snares around farms to prevent wildlife eating crops. Hunting with domestic dogs was the method most commonly used to catch wildlife ( $87 \%$ of households owned dogs). Wild meat was consumed by $84 \%$ of households, and was most frequently bought or caught, but also gifted. We detected a high awareness of conservation rules, but low awareness of punishments and penalties, with wildlife depletion, rather than the risk of being caught by patrols, causing the greatest reduction in hunting. Our findings demonstrate the challenges associated with reliably estimating rule-breaking behaviour and highlight the need to incorporate careful triangulation into study design.
\end{abstract}

Keywords Bushmeat, Cambodia, law enforcement, poaching, protected areas, ranger patrols, snares, unmatched count technique

Supplementary material for this article is available at doi.org/10.1017/So030605319001455

HARRIET IBBETT (Corresponding author, (D) orcid.org/0000-0003-1213-4834), Henry Travers and E. J. Milner-Gulland Department of Zoology, University of Oxford, Oxford, OX1 3SZ, UK. E-mail harriet.ibbett@bangor.ac.uk

Aidan Keane and Andrew D. M. Dobson School of Geosciences, University of Edinburgh, Edinburgh, UK

Olly Griffin Wildlife Conservation Society-Cambodia Programme, Phnom Penh, Cambodia

Received 17 September 2019. Revision requested 13 November 2019.

Accepted 9 December 2019. First published online 23 October 2020.

\section{Introduction}

T unting threatens $25 \%$ of terrestrial mammal species - globally (Ripple et al., 2016), and is estimated to have decreased bird and mammal abundances by 58 and $83 \%$, respectively, in some tropical areas (Benitez-Lopez et al., 2017). The situation is particularly severe in Southeast Asia, where most large wild vertebrate species have declined substantially throughout their remaining ranges (Sodhi et al., 2004; Harrison et al., 2016). Here, forests are increasingly considered empty; i.e. devoid of all but the smallest or most common species (Harrison, 2011), with overexploitation facilitated by advancements in hunting technologies, rapid economic growth and improved access to forested areas (Harrison et al., 2016; Hughes, 2017).

Cambodia is one of the most biodiverse countries in South-east Asia (Daltry, 2008) and is legally one of the best protected, with $34 \%$ of terrestrial land area afforded protected status (Souter et al., 2016). However, in reality protected areas are chronically underfunded, overexploitation of natural resources is widespread, and laws are weakly enforced (Souter et al., 2016). Hunting has probably driven the kouprey Bos sauveli to extinction, extirpated the Javan rhinoceros Rhinoceros sondaicus and tiger Panthera tigris (O'Kelly et al., 2012), and continues to threaten the viability of many other species (Starr et al., 2011; O'Kelly et al., 2012; Rostro-García et al., 2016). Cambodia has a high prevalence of hunting and reliance on wild meat, with an estimated $83 \%$ of rural households engaged in some form of harvest of wild animals at least once per year (Nielsen et al., 2018). Snares are widely used; in 2015, 27,714 were removed by patrols in Cambodia's South Cardamoms National Park (Gray et al., 2016), with true snare abundance probably much higher, as experimental studies suggest only a small proportion of snares set are found by rangers (O'Kelly et al., 2018; Ibbett et al., 2020). Usually made from wire, cable or nylon, snares are affordable, accessible, and have limited selectivity with respect to animals' species, sex or age (Noss, 1998). Once set, they can trap a wide range of arboreal and terrestrial species (Borgerson, 2015; Ingram et al., 2017) and, although animals occasionally escape, subsequent non-fatal injuries often jeopardize long-term survival (Yersin et al., 2017).

The impact of hunting on Cambodia's fauna is well documented (Harrison et al., 2016), but there is less empirical information about hunters, their hunting methods, and local demand for wildlife products (but see Martin \& Phipps, 1996; Loucks et al., 2009; Coad et al., 2019). This 

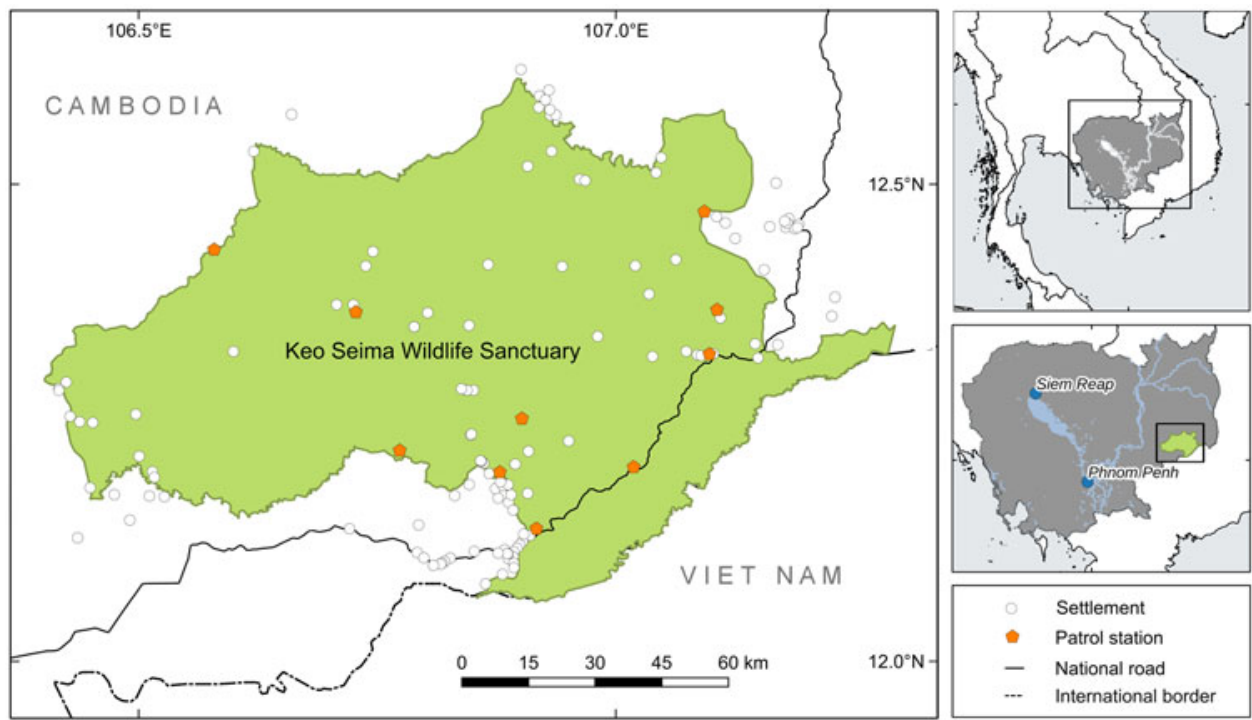

FIg. 1 Keo Seima Wildlife Sanctuary in Mondulkiri Province, Cambodia, indicating all settlements located within and close to the protected area (the 18 study villages are not identified, to ensure anonymity), and ranger patrol stations. may be partly because gathering robust information about hunting is challenging, especially in contexts where it is a restricted or prohibited activity (Nuno \& St John, 2015). Hunting in Cambodian protected areas is a punishable offence (Forestry Administration, 2002; MoE, 2008), and thus those who violate rules may not wish to identify themselves for fear of sanctions (Solomon et al., 2007). When asked directly, respondents may refuse to participate, provide inaccurate responses, conceal their true attitudes, beliefs or behaviours, or temper their answers so as to appear more socially acceptable (known as 'social desirability bias'; Tourangeau \& Yan, 2007; Krumpal, 2013). Acquiring robust and reliable data on hunting prevalence is nonetheless important to ensure conservation interventions are targeted towards the most appropriate groups (St John et al., 2013; Jones et al., 2019).

Here, we quantify the prevalence of hunting amongst rural communities in a Cambodian protected area. We use the unmatched count technique, an indirect questioning approach, to estimate the prevalence of hunting as a subsistence and income-generating livelihood activity. Use of a specialized questioning technique can allow the biases typically associated with direct questioning to be overcome by assuring greater levels of anonymity, although often at the cost of lower precision (Nuno \& St John, 2015). We couple this with direct questioning to derive further information about seasonality, methods used, species caught and consumed, and trends in hunting activity. Finally, we assess local peoples' knowledge of rules regarding the capture and use of wildlife, and their perceptions of the ranger patrols responsible for enforcing protected area rules.

\section{Study area}

Our study was conducted in Keo Seima Wildlife Sanctuary, a $2,927 \mathrm{~km}^{2}$ area of protected mixed deciduous dipterocarp, semi-evergreen and evergreen forest in Mondulkiri and Kratie provinces on the eastern border of Cambodia (Fig. 1; Evans et al., 2012). The Sanctuary lies within a wider forested landscape known as the Eastern Plains, and supports regionally important populations of Asian elephant Elephas maximus, wild cattle Bos spp., and globally important populations of primates (Nomascus gabriellae, Pygathrix nigripes; Griffin, 2019).

Approximately 32,000 people live within and around the Sanctuary, the majority of whom are Bunong, an animist minority Indigenous people who have strong spiritual connections to the forest and its wildlife. Traditionally, the Bunong practised swidden agriculture, and relied heavily on non-timber forest products (NTFPs) such as honey, fish, rattan, wild fruit, vegetables and wildlife for subsistence (Evans et al., 2003). The construction of roads has brought market integration to previously inaccessible villages and strengthened cross-border trade links with Viet Nam (Mahanty \& Milne, 2016). Many households have abandoned traditional swidden agricultural practices in favour of more profitable cash crops such as cassava and cashew (Travers et al., 2015). Villages, particularly those on the periphery, have experienced large influxes of Khmer (the majority ethnic group in Cambodia) families seeking land, and forest cover has declined as a result of subsequent clearance for small-scale farms (Mahanty \& Milne, 2016; Riggs et al., 2018). In addition, the forest has experienced severe pressure from illegal logging for luxury timber, as well as industrial-scale forest clearance associated with government granting of Economic Land Concessions within protected area boundaries.

Prior to 2016, Keo Seima Wildlife Sanctuary was managed as a Protection Forest by the Government's Forestry Administration. In 2016 jurisdictional reforms of natural resource management resulted in transfer to the Ministry of Environment under sub-decree 83, and reclassification as a Wildlife Sanctuary, with the principal objective 
of preserving and protecting wildlife (MoE, 2016). According to the 2002 Forestry Law, it is strictly prohibited to hunt, harm or harass all wildlife, and under the 2008 Protected Area Law, killing wildlife and releasing hunting dogs is strictly forbidden, and regulated extraction of NTFPs and sustainable use is allowed in some zones within the protected area (MoE, 2008). Hunting occurs throughout the Sanctuary, however, and previous research has highlighted the reliance of local communities on wild meat for subsistence purposes (Travers, 2014) and to supplement income. Hunting is also undertaken by outsiders (i.e. people who do not live within or immediately around the forest) for sport, commercial purposes and subsistence (Drury, 2005; Evans et al., 2013). Responsibility for enforcing rules lies with 40-50 government rangers working across $10 \mathrm{pa}-$ trol stations. Since 2002 the government has received financial and technical support for the management of the Sanctuary from the Wildlife Conservation Society.

\section{Methods}

\section{Ethical considerations}

Upon arrival in each village, we met the village chief to explain our research aims and seek permission to work in the community. Before each interview the research purpose, risks, benefits, and proposed use of the data were explained to participants before verbal consent was sought (Supplementary Material 1). All interviews were voluntary, anonymous, and conducted in Khmer or Bunong by independent enumerators unassociated with the Wildlife Conservation Society. Hunting is illegal, and therefore to protect participants against reprisals questions on hunting were targeted at the household rather than individual level, and village names have been anonymized here to offer additional protection. All methods were piloted before data collection, in 33 households during February 2018.

\section{Household surveys}

During February-April 2018, we interviewed people in 705 households in 18 villages (Fig. 1). Between 30 and $50 \%$ of households were surveyed per village, with houses identified using a systematic sampling strategy in which questionnaires were administered at every nth house, with $n$ inversely related to village size. We interviewed any available respondent above the age of 18 in each household. If respondents declined or were absent, interviews were conducted at the next available house. Enumerators collected data on respondent demographics and household livelihood strategies, household reliance on wildlife species for meat and medicine, specifically the frequency with which species were consumed, how wildlife was accessed, and the most preferred meat (Supplementary Material 1 \& 2). Respondents were also asked about any problems with wildlife on farms, and their perceptions of any change in hunting levels over the previous 5 years.

\section{Measuring hunting prevalence}

To reduce social desirability and non-response biases, we used the unmatched count technique to investigate the proportion of households that collected wild meat, took snares to the forest to hunt, and hunted to generate income in the previous year. Half the sample were randomly allocated to a control group who received a list of non-sensitive items, and the treatment group received a list that included the same nonsensitive items, plus an additional sensitive item (Nuno \& St John, 2015). Respondents were asked to report only the number of items applicable to them, never which items. Item scores were averaged across groups, and the prevalence of the sensitive item was estimated from the difference between the means. The unmatched count technique requires large sample sizes, and estimates can have wide standard errors (Hinsley et al., 2019); to mitigate against this, we employed a double-list unmatched count technique, in which participants simultaneously act as control and treatment groups by answering a control and treatment list for the same question, but with the set of non-sensitive items differing between the two lists (Droitcour et al., 2011). Prevalence of the sensitive item is derived by calculating the mean score across the paired lists (Glynn, 2013). Because of high levels of illiteracy, pictorial lists were used, and items were verbally described to participants. A practice question on fruit consumption was used to introduce the method, and follow-up questions were asked to assess respondents' understanding. At the end of the interview, respondents were asked directly whether they currently or had ever hunted and, if so, the species they caught, how often they hunted, the methods used, and their reasons for hunting.

\section{Knowledge of conservation rules}

We assessed knowledge of rules pertaining to hunting activity, and the perceived likelihood of (1) a neighbour knowing if someone had caught wildlife, (2) being caught by a patrol when hunting and (3) receiving a penalty if caught. We measured social acceptability by asking respondents whether they would approve if a friend or family member went hunting. Finally, we asked households whether they had ever been caught by a patrol in possession of wildlife, and if so what happened.

\section{Analysis}

Prior to analysis, unmatched count technique data were tested to determine whether individual responses to the non-sensitive item changed depending upon the 
respondents' treatment status (design effects). This test was conducted using the ict.test function in the list package of $R$ 3.2.1 (Blair et al., 2016; $\mathrm{R}$ Core Team, 2017). If a Bonferroni-corrected $\mathrm{P}$-value of $<0.05$ was detected, this was interpreted as evidence for the presence of design effects, which were detected for one list (Supplementary Material 3). In addition, both floor and ceiling effects were detected for all lists. Floor effects occur if a higher than expected number of respondents give an aswer of o (i.e. none of the items were applicable), and ceiling effects occur if the maximum number of items is reported for each list (i.e. all the items were applicable). Both effects reduce anonymity and indicate the method did not function as expected. Prevalence estimates were calculated by combining the scores from list pairs using the ictreg function in $R$.

\section{Results}

In total, $56 \%$ of respondents were men, $44 \%$ were women. Respondents were Bunong (66\%), Khmer (31\%) or from other Indigenous groups (Stieng, Laotian, Cham; $3 \%$ ). Respondents had lived in their village for a mean of $17 \pm$ SD 12.8 years, with $3 \pm$ SD 3.5 years of formal education. The main sources of household income were farming (66\% of households), shops or businesses (11\%), resin collection (9\%), opportunistic paid labour (7\%), salaried work (5\%) or illegal logging (2\%). Eighty-four per cent of households collected NTFPs, and $23 \%$ collected resin.

\section{Wildlife hunting}

\section{Hunting prevalence, frequency \& seasonality}

When directly questioned, $9 \%$ of households reported hunting, and $27 \%$ of households reported they used to hunt but no longer did. When asked to indicate the year they ceased hunting (Fig. 2), 82\% of hunters indicated they stopped hunting after 2009. Reasons included increased difficulty in catching wildlife ( $43 \%$ of retired hunters), reduced time available for hunting ( $35 \%)$, lack of dogs to hunt with $(8 \%)$, old age $(7 \%)$ and concern about meeting law enforcement patrols $(5 \%)$. The unmatched count technique warm-up question regarding prevalence of fruit consumption appeared to work as expected, estimating $25 \pm$ SE $9 \%$ of respondents consumed the sensitive fruit, but the question on hunting provided a negative prevalence estimate (Fig. 3). Ideally, no respondent should report that all items on either the control or treatment list were applicable to them (i.e. nobody should answer 4 or 5), but responses to the question were subject to ceiling effects, meaning some respondents reported all items on the lists were applicable. Although this undermines assurances of anonymity (because the interviewer knows the sensitive answer applies to the respondent), it provides a direct count of households

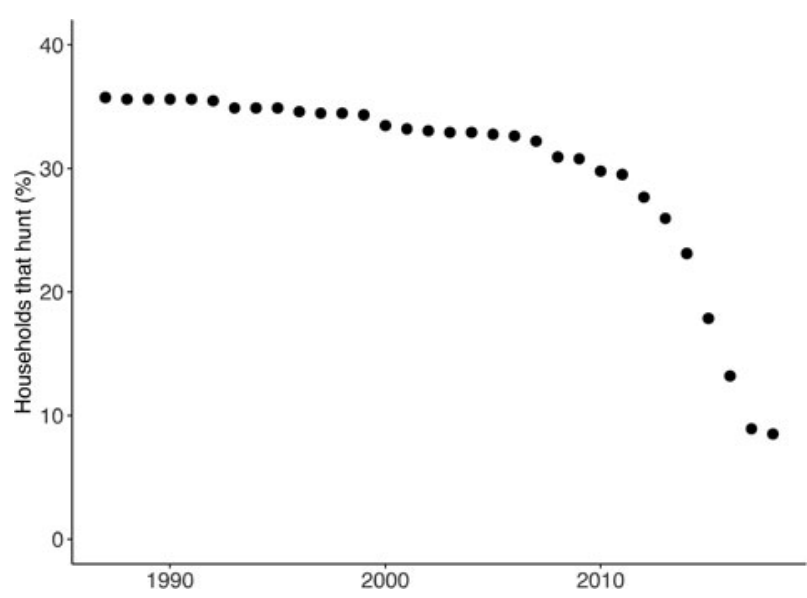

FIg. 2 Temporal change in the prevalence of hunting reported by 705 respondents in Keo Seima Wildlife Sanctuary in 2018.

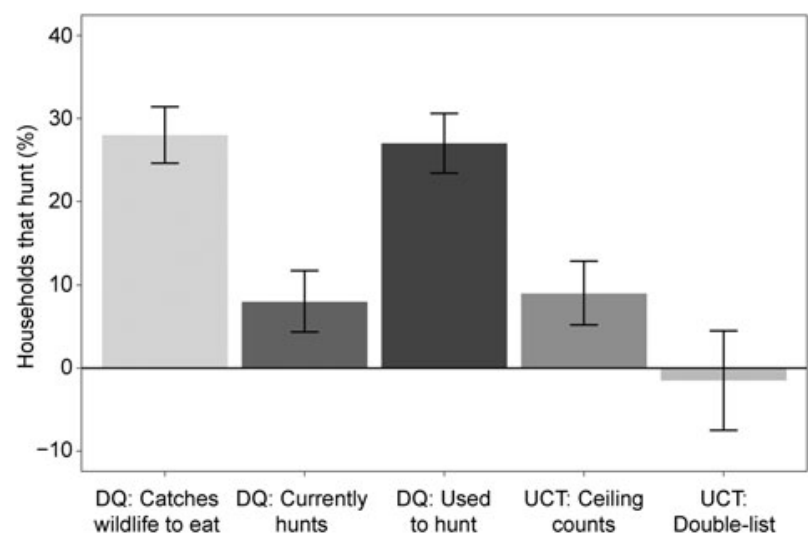

FIg. 3 Triangulated estimates of hunting prevalence in Keo Seima Wildlife Sanctuary, with $95 \%$ confidence intervals. DQ indicates questions in which 705 respondents where asked directly about hunting. UCT indicates findings from the unmatched count technique (702 of 705 respondents answered questions).

who reported hunting (63, 9\%; Fig. 3). Unmatched count technique estimates for taking snares to the forest and hunting for income were also unreliable and did not significantly differ from zero (Supplementary Material 3).

In households where people directly reported hunting ( $9 \%$ of all respondents) there was a mean of 4.31 hunting trips per month, almost double the number reported by retired hunters (27\% of respondents, 2.45 trips per month). When asked what they would do if hunting became harder (i.e. wildlife was caught less frequently), $52 \%$ of current hunters would stop, $27 \%$ would seek new hunting grounds, $17 \%$ would continue to collect other NTFPs (hunting if the opportunity arose), $2 \%$ would change method, and $2 \%$ were unsure. Seventyseven per cent of all respondents thought more hunting occurred in the wet season when the absence of leaf litter on the forest floor made it easier to walk quietly in the forest, snares could be set around fruiting trees such as wild almond 
Irvingia malayana, and wildlife was easier to catch as animals were distracted while foraging on new growth. In addition, it was reported that lulls in agriculture and logging meant people had more time to allocate to hunting, and poor road conditions reduced the chance of encountering ranger patrols. Six per cent of respondents indicated hunting was more frequent in the dry season when the absence of foliage made it easier for dogs to run unhindered, and when water scarcity meant efforts could be targeted around water sources. Seventeen per cent of respondents did not know when most hunting occurred.

\section{Hunting methods}

Dogs were the most commonly reported hunting method ( $87 \%$ of 60 current hunters), followed by slingshot (47\%), snares $(13 \%)$ and crossbow ( $3 \%$; Table 1$)$. Only $7 \%$ of all respondents reported ever having set snares in the forest, and only eight interviewees reported currently doing so (1\%), setting a mean of 46 snares, although one respondent reported maintaining 500 snares.

People in $35 \%$ of current hunting households reported using more than one method to catch wildlife. Dogs and slingshots were reported more frequently by current hunters than retired hunters, with snares, crossbows and guns reported less frequently by current hunters (Table 1). Respondents often said that guns were only used by people outside the community or authorities, such as police or the military. Several respondents reported seeing soldiers hunting primates, with guns, and another stated they had seen men with rifles, in $4 \times 4$ vehicles, with cool-boxes to take meat away. One respondent said they had borrowed a gun from the police to shoot black-shanked douc langur $P$. nigripes.

Of those that reported hunting, $68 \%$ said they did so only for subsistence, $28 \%$ hunted for food and income, and only one household reported hunting solely for income. One individual said that, if successful, they could earn USD 250-500 per month selling meat to villagers or external traders. This is considerably more than the monthly earnings of a casual labourer, which are KHR 15,000-30,000 per day (USD 80150 per month). The most commonly caught species were monitor lizard (Varanus spp., $71 \%$ of current hunters), wild boar Sus scrofa (28\%), chevrotain (Tragulus spp., 13\%) and civets (Paradoxurus hermaphroditus, Viverra zibetha, 12\%; Table 2). Other species caught included northern red muntjac Muntiacus vaginalis, sambar Rusa unicolor, long and pigtailed macaque (Macaca fascicularis, Macaca nemestrina), blackshanked douc langur, southern yellow-cheeked crested gibbon Nomascus gabriellae, Sunda colugo Galeopterus variegatus, red jungle fowl Gallus gallus, and various tortoise, turtle and squirrel species. Compared to retired hunters, a greater proportion of current hunters reported catching monitor lizards and civets, and fewer reported catching wild boar, muntjacs and chevrotains (Table 2).
TABLE 1 Hunting methods reported by a total of 192 retired hunters ( $27 \%$ of respondents surveyed) and 60 current hunters ( $8 \%$ of respondents surveyed) in Keo Seima Wildlife Sanctuary, Cambodia, in 2018 .

\begin{tabular}{lll}
\hline Method & $\begin{array}{l}\text { No. of retired } \\
\text { hunters (\%) }\end{array}$ & $\begin{array}{l}\text { No. of current } \\
\text { hunters }(\%)\end{array}$ \\
\hline Dogs & $155(81)$ & $52(87)$ \\
Slingshot & $73(38)$ & $28(47)$ \\
Snares & $40(21)$ & $8(13)$ \\
Crossbow & $12(6)$ & $2(3)$ \\
Gun & $5(3)$ & $0(0)$ \\
\hline Total no. of respondents & 192 & 60 \\
\hline
\end{tabular}

\section{Protecting crops}

Alongside killing wildlife for food, medicine and income, respondents reported killing wildlife to protect crops. Seventy-one per cent of all households reported that wildlife ate or destroyed crops, and $20 \%$ reported setting snares (a mean of 20 per household) around farms to protect crops. Four per cent of households reported setting 100-300 snares. The main problem species reported were the wild boar ( $85 \%$ of respondents with wildlife problems), long-tailed macaque (52\%), elephant (32\%) and green peafowl Pavo muticus (24\%). Other species mentioned included the East Asian porcupine Hystrix brachyura, red muntjac, jungle fowl and bamboo rat (Rhizomyini spp.).

\section{Hunting by dogs}

Seventy-nine per cent of households owned dogs, and $45 \%$ of those who went to the forest took dogs with them for companionship and for protection against encounters with wildlife. Although a few respondents reported actively using dogs to hunt species such as muntjac and sambar, many of those who reported dogs killing wildlife said it was unintentional. When accompanying owners to the forest, dogs would chase wildlife scents. Owners also reported dogs roaming away from home to hunt, catching species such as monitor lizards, chevrotains, turtles and tortoises. Excluding puppies, we recorded a total of 1,633 dogs; the mean number of dogs owned across all 705 households was 2.31 (a mean of 2.91 dogs per 557 dog-owning households). Approximately $40 \%$ of households were surveyed, suggesting the total number of domestic dogs living within Keo Seima Wildlife Sanctuary could exceed 4,000, or 1.36 per $\mathrm{km}^{2}$, a higher density than many species of conservation interest (Wildlife Conservation Society, unpubl. data).

\section{Wildlife use and consumption}

Eighty-five per cent of all households consumed wild meat, and $45 \%$ used wildlife products for medicinal purposes. Overall, $70 \%$ of respondents preferred eating wild meat 
TABLE 2 Species most commonly caught, as reported by a total of 252 current and retired hunters in Keo Seima Wildlife Sanctuary, Cambodia, in 2018.

\begin{tabular}{llll}
\hline Species & National status (Red List status ${ }^{1}$ ) & No. of retired hunters (\%) & No. of current hunters (\%) \\
\hline Monitor lizard Varanus spp. & Common (LC) & $116(60)$ & $43(71)$ \\
Wild boar Sus scrofa & Common (LC) & $78(41)$ & $17(28)$ \\
Chevrotain Tragulus spp. & Unclassified (LC) & $46(24)$ & $8(13)$ \\
Northern red muntjac Muntiacus vaginalis & Common (LC) & $26(15)$ & $2(3)$ \\
Civets $^{2}$ & Common (LC) & $9(5)$ & $7(12)$ \\
Primates & Common/Rare (LC/EN) & $11(6)$ & $3(6)$ \\
Sambar Rusa unicolor & Common (VU) & $2(1)$ & $1(<1)$ \\
\hline Total no. of repondents & & 192 & 60 \\
\hline
\end{tabular}

${ }^{1}$ LC, Least concern; VN, Vulnerable; EN, Endangered.

${ }^{2}$ Common palm civet Paradoxurus hermaphroditus and large Indian civet Viverra zibetha.

${ }^{3}$ Long-tailed/pig-tailed macaque Macaca fascicularis/nemestrina: Common/LC; black-shanked douc langur Pygathrix nigripes and yellow-cheeked crested gibbon Nomascus gabriellae: Rare/EN.

TABLE 3 Reasons given by 705 respondents living in Keo Seima Wildlife Sanctuary when asked about their preference for different types of meat in 2018 (six respondents indicated they had no preference, and six did not answer the question).

\begin{tabular}{lll}
\hline & \multicolumn{2}{l}{ Meat type preferred } \\
\cline { 2 - 3 } Reason for preference & Wild meat $(\%)$ & Domestic meat $(\%)$ \\
\hline It is better for your health & $299(42)$ & $16(2)$ \\
It has no chemicals & $235(33)$ & $5(<1)$ \\
It is tastier & $209(30)$ & $21(3)$ \\
It is natural & $58(8)$ & - \\
It is more affordable & $1(<1)$ & $7(<1)$ \\
It is easier to buy & - & $122(17)$ \\
\hline Total no. of respondents & $490(70)$ & $166(24)$ \\
\hline
\end{tabular}

to domestic alternatives, mostly because wild meat was believed to be healthier, free from chemicals, and chnganh (delicious) (Table 3). Twenty-four per cent of respondents preferred domestic meat, mostly because it was more accessible. Domestic meat was reportedly more widely sold, and easier to buy in small quantities, than wild meat, which was usually only sold by the kilogram. Several respondents said wild meat could unknowingly be bought, as it is difficult to differentiate meat once butchered. Only $4 \%$ of respondents who preferred domestic meat cited affordability, and prices often overlapped. Wild boar, for example, was USD $3.75-6.25$ per $\mathrm{kg}$ in villages, whereas domestic pork in the district town (which is usually cheaper for commodities in general than villages) was USD 3-4.5/kg. Muntjac and sambar meat was less available, and more expensive than wild boar meat (village price USD 5-8.75/kg).

Respondents reported accessing wild meat in several ways. It was most commonly ( $78 \%$ of respondents) bought from villagers or motorcycle traders from the district town. Some said traders hid meat in compartments under their motorbike seats. Thirty-three per cent of respondents reported catching wild animals to eat, which is surprising considering only a small proportion $(9 \%)$ reported hunting;
$20 \%$ reported being given wild meat by family or neighbours. More households ate wild meat in the wet $(90 \%$ of consumers) than in the dry season $(73 \%)$, with wild meat also consumed more frequently in the wet (mean 1.79 times per month) than in the dry season (mean 0.95 times per month). This corroborates the reportedly higher frequency of wildlife interactions in the wet season, when species can be caught eating crops. In addition, domestic meat alternatives were reportedly less available during the wet season, as rain restricts traders' access and villagers have less income to purchase domestic meat.

The species most commonly reported as eaten were wild boar (79\%), monitor lizard (30\%), muntjac (22\%), chevrotain (11\%), monkeys (4\%), civets (3\%), sambar (3\%), tortoises and turtles $(3 \%)$ and jungle fowl (2\%). Snakes, porcupine and other rodents accounted for $<1 \%$ each. Species most likely to be bought were wild boar, monitor lizard and red muntjac. Species most likely to be caught were monitor lizard, wild boar, chevrotain and muntjac, and monitor lizard was most likely to be gifted (Table 4). The most common species used for medicine were the slow loris Nycticebus pygmaeus ( $83 \%$ of households) and the porcupine $(77 \%)$. In some villages, slow loris could be ordered from local hunters, who caught them at night using spotlights and slingshots. Others bought slow loris or porcupine from neighbours or traders, when available. One respondent reported that a tonic made from rice wine and slow loris, traditionally given to mothers after childbirth, could be purchased at one of the provincial markets. Other species mentioned more than once for medicinal purposes included chevrotain ( $12 \%$ of households), cobra (Naja spp., 4\%), flying squirrel (Pteromyini, 4\%), muntjac $(2 \%)$, civet $(2 \%)$, black-shanked douc (2\%), Sunda pangolin Manis javanica (1\%) and hornbill (Bucerotidae spp., $<1 \%$ ).

The majority of respondents believed that since 2013 levels of hunting ( $82 \%$ of respondents), wildlife consumption $(90 \%)$ and sale of wildlife by villagers $(89 \%)$ had decreased. Fifty-four per cent of respondents believed hunting levels had declined because wildlife was scarcer and 
TABLE $4 \chi^{2}$ tests of association between whether a species was reported as consumed by a household, and how wild meat was accessed (with 1 degree of freedom). All species reported as eaten were tested, but only species for which there were positive associations with access type are reported.

\begin{tabular}{llrl}
\hline $\begin{array}{l}\text { How household } \\
\text { accessed wild meat }\end{array}$ & $\begin{array}{l}\text { Species household } \\
\text { reported consuming }\end{array}$ & \multicolumn{1}{l}{$\chi^{2}$} & $\mathrm{P}$ \\
\hline Bought & Wild boar & 58.266 & $<0.001$ \\
& Monitor lizard & 19.338 & $<0.001$ \\
& Muntjac & 18.362 & $<0.001$ \\
Caught & Monitor lizard & 121.020 & $<0.001$ \\
& Wild boar & 40.765 & $<0.001$ \\
& Chevrotain & 20.410 & $<0.001$ \\
Gifted & Muntjac & 7.271 & 0.007 \\
& Monitor lizard & 4.941 & 0.026 \\
\hline
\end{tabular}

therefore harder to catch, $13 \%$ thought patrols deterred people, $10 \%$ said forest loss meant there was nowhere to hunt, and $9 \%$ said livelihood changes meant people were now too busy farming cash crops to hunt. Reasons freely given by respondents for these changes included growing village populations increasing demand for wildlife, and because hunters secretly sold wildlife to traders. Others suggested that increasing village populations meant people were less inclined to share wild meat with neighbours, to avoid having to share wild meat with many people. Fiftytwo per cent of respondents believed that hunting by outsiders had decreased, $38 \%$ of respondents did not know or thought hunting was not undertaken by outsiders, and $9 \%$ thought hunting by outsiders had increased. Outsiders were typically regarded as people from outside the commune. Some respondents stated that declines in hunting by local people meant there was more wildlife, which attracted outsiders to hunt.

\section{Law enforcement}

\section{Knowledge of rules}

Seventy-one per cent of respondents stated there were rules about catching wildlife. Of these, $26 \%$ attributed their knowledge of rules to the Wildlife Conservation Society (e.g. 'WCS said we cannot catch wildlife'). Twenty-seven per cent did not know if there were rules, and $2 \%$ believed there were none. When asked specifically about setting snares around farms, $26 \%$ of respondents incorrectly believed it was legal, $45 \%$ correctly said it was not and $29 \%$ did not know.

The majority of respondents $(78 \%)$ thought that if a member of their household went hunting, their friends and/or family would disapprove. However, some respondents explained that it depended on what was caught; using dogs to catch small animals, such as monitor lizards or turtles, for food, was considered acceptable, whereas shooting large

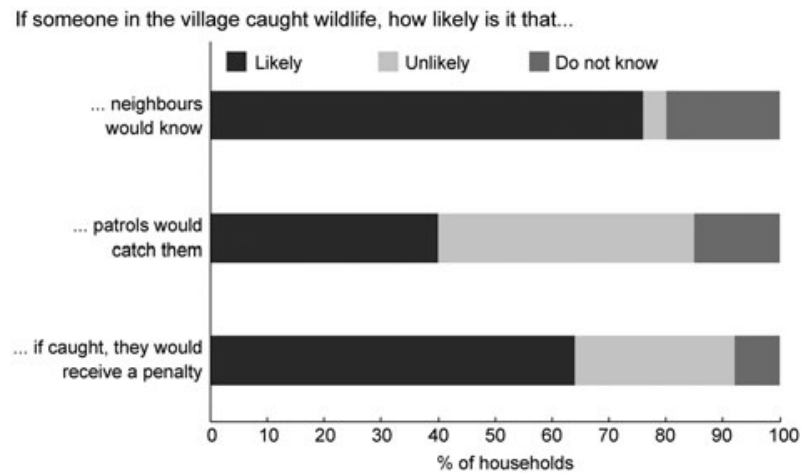

FIG. 4 The perception of 705 respondents regarding whether neighbours would know about a villager's hunting activity, a villager being caught by a patrol if hunting, and a villager receiving a penalty if caught by a patrol in Keo Siema Wildlife Sanctuary.

animals, such as elephants, was not. Twelve per cent of respondents thought others would approve of hunting, and $10 \% \mathrm{did}$ not know or had no opinion. If someone in the village caught wildlife, $76 \%$ of respondents thought it likely that neighbours would know (Fig. 4). Some respondents said it was difficult to keep it secret because children would spread the news, although secrecy would allow people to avoid sharing their catch and reduce the risk of being reported.

\section{Perceptions of law enforcement effectiveness}

If a villager hunted, only $40 \%$ of respondents thought it likely that a patrol would catch them, but if caught, $64 \%$ thought it likely a hunter would receive a penalty (Fig. 4). Expected penalties listed by respondents included arrest ( $45 \%$ of respondents), warning (16\%), fine (15\%), and confiscation of meat and/or snares (13\%). Twenty-four per cent of respondents did not know what the penalty would be. Respondents often stated that the type of penalty received depended on the severity of the crime, and whether the hunter had previously been caught. Some reported that if they were only hunting for food, and had caught only small animals such as wild boar, monitor lizards or tortoises, patrols may show leniency. However, if caught hunting large animals such as elephants, sambar or gaur, punishment could be a fine of up to USD 2,000 or imprisonment.

Despite respondents saying there was a $40 \%$ probability of being caught when hunting, overall, just 13 respondents ( $7 \%$ of all those who reported ever hunting) had been caught by a patrol when hunting, and only once did a household report severe punishment. In this incident, the respondent's son had been lent a gun by the police to shoot sambar. After his arrest by rangers, the police reportedly intervened and, rather than being prosecuted, the son was released with a fine of USD 500. Mostly, respondents reported receiving warnings or having meat confiscated. 


\section{Perceptions of patrols}

Sixty-two per cent of respondents reported they were not worried about encountering patrols in the forest. The majority said that as they did not hunt or partake in any illegal activities they had nothing to fear, although a small number of respondents expressed concern that patrols might prevent or punish the legal collection of NTFPs, such as rattan. Others reported adapting their behaviour to avoid patrols, for example by waiting until patrols had passed. Some said friends and family would call to warn them if patrols passed through the village towards the forest. One respondent said when hunting in a group, each would travel individually to reduce the chance of being spotted by a patrol, and meat would be shared in the forest before leaving, to reduce punishment if caught. In total, $37 \%$ of respondents expressed concern about meeting patrols, of which $21 \%$ said that this was because a member of their household was engaged in illegal logging. A further $25 \%$ of respondents said they were worried that rangers would punish them if their dogs caught wildlife. Several respondents believed that camera traps set by the Wildlife Conservation Society to monitor wildlife populations were actually set to photograph people hunting.

\section{Corruption}

We frequently found that respondents associated patrols with corruption. One individual stated 'patrols only come to catch the money, not to stop people', and another stated 'patrols only use laws for villagers, they have different rules for outsiders or people with power'. One respondent, who was a commercial hunter, reported they avoided punishment because they were on friendly terms with rangers, and other respondents reported that if hunters were caught, rangers would ask for or accept a bribe. Others believed that when rangers confiscated meat, they ate it themselves instead of destroying it. After one interview a respondent reported they had found a muntjac fawn in the forest, but when urged to take it to the nearest patrol station, they refused, as they believed that the rangers may eat it. Nobody explicitly reported having paid a bribe when caught hunting, but two respondents said they had paid bribes to patrols when transporting wood, and others reported they had heard that other villagers paid bribes to release confiscated motorbikes. One respondent said that bribery occurs because the low-paid rangers have to pay their superiors, to maintain their positions.

\section{Discussion}

Hunting is widely cited as a cause of the loss of biodiversity in Cambodia (Harrison et al., 2016; Gray et al., 2017). Our research confirms that local communities living in Keo Seima Wildlife Sanctuary do hunt, although there is uncertainty regarding prevalence. Direct questioning and ceiling counts from the unmatched count technique suggest a prevalence of $9 \%$, but the estimate from the latter did not differ significantly from zero. This is probably the result of floor and ceiling effects, which reduce precision, as well as anonymity (Blair et al., 2016). Our findings also highlight ambiguity regarding the definition of hunting; one-fifth of respondents reported setting snares around farms, which was considered a legitimate crop protection activity, and when people were asked about how they accessed wild meat to eat, nearly a third said they caught their own wild meat, presumably from snares set around farms. Yet, few households stated they hunted. Our results suggest that questions about the intentional killing of wildlife in the forest were probably subject to bias, and that responses about wildlife killed opportunistically (e.g. by dogs) or coincidentally (e.g. to protect crops) were less likely to be censored, a matter also documented elsewhere in Cambodia (Coad et al., 2019). Our findings reinforce the need to consider survey questions carefully, and to triangulate by asking several questions, in different ways, about the same topic, particularly if examining sensitive topics. During our research, some respondents were hushed by fellow family members when discussing hunting, and others failed to mention information they later provided after questionnaires were completed (e.g. borrowing guns). Overall, it is likely our findings underestimate hunting prevalence.

Although specialized methods such as the unmatched count technique can be useful for reducing biases associated with sensitive topics, they require careful design, extensive piloting and are not suitable for all contexts (Hinsley et al., 2019). Greater understanding of the reliability of these methods for providing robust estimates of rule-breaking behaviour is needed. Typically, estimates derived from specialized questioning techniques are validated by comparing them to those obtained from direct questioning; if prevalence estimates from the specialized method are higher, the method is perceived as more successful. In addition to undermining the anonymity of the method (Ibbett \& Brittain, 2019), this validation approach fails to inform researchers whether respondents understood the method and felt sufficiently protected to report their behaviour accurately. Typically, conservation research focuses on obtaining data to answer urgent questions, rather than testing methods per se. Yet, experimental studies that explictly assess methods such as the unmatched count technique would enhance research practice and improve the reliability of data used to inform conservation interventions.

Snaring has been identified as a specific threat to Cambodia's wildlife (Harrison et al., 2016; O'Kelly et al., 2018) but, although snares were widely used to protect crops, few respondents reported setting snares to hunt wildlife in the forest. Snaring by ex-hunters, who theoretically have less incentive to misreport behaviour, was also low. 
We suspect that only a few individuals in each village hunt for commercial purposes, probably facilitated by middlemen who may place orders, purchase catch, and in some cases supply equipment, as documented elsewhere in Cambodia (Gray et al., 2017; Coad et al., 2019). One limitation of our research is that our study was restricted to the hunting activity of local people, although hunting is also thought to be undertaken by Vietnamese nationals near the international border (O'Kelly et al., 2018), by logging gangs who stay in the forest for extended periods (HI, pers. obs., 2017), and by military or police personnel with high-powered rifles (Drury, 2005; Evans et al., 2013). Gathering information on prevalence of hunting by these groups should be a research priority, although such research could potentially pose significant risk to researchers.

Our findings highlight a threat to wildlife from hunting by domestic dogs, an issue identified elsewhere in Cambodia (Heng et al., 2016; Loveridge et al., 2018). The scattered distribution of villages, combined with the frequent accompaniment of hunters by dogs, means that interactions between dogs and wildlife are likely to occur regularly throughout the protected area. The presence of dogs may also have indirect impacts on wildlife, by inducing fear in wild animals, increasing competition for resources with wildlife, and transmitting disease (Gompper, 2014). To understand the potential threats that dogs pose to wildlife more information is needed on the ranging and hunting behaviour of dogs (e.g. by using faecal analysis or GPS tracking), alongside socially acceptable interventions that promote responsible dog ownership. For example, preliminary surveys by the Wildlife Conservation Society suggest communities are concerned about the high dog population but lack the means to deliver humane sterilization. A free dog sterilization programme could be one possible solution, although a high proportion of dogs would need to be sterilized to achieve a sufficient reduction in the population (O. Griffin, unpubl. data).

Traditionally, hunting in Keo Seima Wildlife Sanctuary was conducted during resin collection (Drury, 2005). However, since 2008 resin collection has declined markedly (Cheetham, 2014), partly because of reduced profitability but also because of the loss of resin trees to illegal logging and industrial-scale land clearance, which intensified in c. 2013. Cash cropping has emerged as the primary form of income generation (Travers et al., 2015; Mahanty \& Milne, 2016), and therefore many have less time to develop hunting skills and spend time hunting, and more income to buy wild meat (Coad et al., 2019). Looking ahead, infrastructural improvements, such as paved roads and improved cellular networks, may further enhance the market integration of villages within the Sanctuary (Riggs et al., 2018), boosting the prevalence of cash cropping and reducing economic reliance on traditional livelihood activities.

Fluctuations in cash crop prices, declining soil fertility, and high costs of fertilizers, pesticides and land rents, has contributed to increasing debt burdens within local communities (Mahanty \& Milne, 2016). Our findings suggest consumption of wild meat is widespread but low, comprising only a few meals per month. Historically, forest products such as wildlife have provided communities with a safety net in times of hardship (Milner-Gulland et al., 2003) but economic vulnerability associated with growing debt may result in increased pressure on natural resources, including wildlife. This could be exacerbated by infrastructural improvements, which may enhance local, provincial and regional access to wildlife trade. Intelligence-gathering operations that assess commodity chains would be beneficial for an understanding of demand dynamics, but in-depth understanding of the norms and attitudes driving consumption is also required. To be effective, any intervention for behavioural change must be informed by robust evidence, and include appropriate monitoring and impact evaluation (Veríssimo \& Wan, 2019).

Central to the success of protected areas is that rules governing natural resource use are widely known (Keane et al., 2011) and, once known, adhered to (Arias, 2015). Patrols are deployed to catch those who commit offences and to act as a deterrent to potential offenders (Dobson et al., 2019). Regardless of whether law enforcement is effective, if the perceived likelihood and cost of being caught are high, we would expect people should be less likely to offend. Our findings suggest the effectiveness of patrols as a strategy to reduce hunting varied. The perceived likelihood of being caught was low, but the perceived likelihood of incurring a punishment if caught was high. These factors combined were sufficient to deter some individuals from hunting, and caused others to develop patrolavoidance strategies. Yet, rangers were also perceived to unjustly punish local people, although some considered rangers' malleability, in particular their alleged willingness to accept a bribe, to be advantageous. Although we agree with the recommendations of others (more efficient and intelligence-led patrolling is needed, legislation that criminalizes hunting and possession of technologies such as snares is required, and all aspects of judiciary systems need to be strengthened; Gray et al., 2017), we believe that conservation success is unlikely to be achieved by strengthened law enforcement alone (Travers et al., 2016). Any approach must be informed by adequate understanding of the drivers of non-compliant behaviour, together with clear recognition of the incentives most likely to encourage behavioural change.

Acknowledgements We thank Nao Sok, Sovanndara Than and Sovann Nharak for collecting data; Wildlife Conservation Society Cambodia and the Royal Government of Cambodia's Ministry of Environment for their support, facilitation and input into the research. Research was funded by the UK Natural Environment Research Council (Grant No. NE/N001370/1).

Author contributions Research conception and design: all authors; data collection and analysis, lead writing: HI; writing and revision: all authors. 
Conflicts of interest Keo Seima Wildlife Sanctuary receives financial and technical support from the Wildlife Conservation Society Cambodia Programme, with whom OG is affiliated.

Ethical standards Research permission was granted by the Royal Government of Cambodia, ethics clearance approved by the University of Oxford's Social Sciences \& Humanities Interdivisional Research Ethics Committee (Ref No: R43030/RE004), and the research otherwise abided by the Oryx guidelines on ethical standards.

Data availability Data are available from reshare.ukdataservice.ac. uk/854333.

\section{References}

ArIAs, A. (2015) Understanding and managing compliance in the nature conservation context. Journal of Environmental Management, 153, 134-143.

Benitez-Lopez, A., Alkemade, R., Schipper, A.M., Ingram, D.J., Verweij, P.A., Eikelboom, J.A.J. et al. (2017) The impact of hunting on tropical mammal and bird populations. Science, $356,180-183$.

Blair, G., Imai, K., Park, B., Coppock, A. \& Chou, W. (2016) List: Statistical Methods for the Item Count Technique and List Experiment. R Foundation for Statistical Computing, Vienna, Austria. rdrr.io/cran/list [accessed 17 March 2020].

Borgerson, C. (2015) The effects of illegal hunting and habitat on two sympatric endangered primates. International Journal of Primatology, 36, 74-93.

Cheetham, S. (2014) Tapping for Change: Investigating the Dynamics of Resin Tapping in Seima Protection Forest, Cambodia. Imperial College London, London, UK.

CoAd, L., Lim, S. \& NuOn, L. (2019) Wildlife and livelihoods in the Cardamom Mountains. Frontiers in Ecology and Evolution, 7, 296.

Daltry, J. (2008) Editorial-Cambodia's biodiversity revealed. Cambodian Journal of Natural History, 2008, 3-5.

Dobson, A.D.M., Milner-Gulland, E.J., Beale, C.M., Ibbett, H. \& Keane, A. (2019) Detecting deterrence from patrol data. Conservation Biology, 33, 665-675.

Droitcour, J., Caspar, R.A., Hubbard, M.L., Parsley, T.L., Visscher, W. \& Ezzati, T.M. (2011) The item count technique as a method of indirect questioning: a review of its development and a case study application. In Measurement Errors in Surveys (eds P.P. Biemer, R.M. Groves, L.E. Lyberg, N.A. Mathiowetz \& S. Sudman), pp. 185-210. John Wiley \& Sons, New Jersey, USA.

DruRY, R. (2005) Wildlife Use and Trade in Seima Biodiversity Conservation Area, Mondulkiri Province, Cambodia. University College London, London, UK.

Evans, T.D., Hout, P., Phet, P. \& Hang, M. (2003) A Study of Resin-Tapping and Livelihoods in Southern Mondulkiri, Cambodia, with Implications for Conservation and Forest Management. Wildlife Conservation Society Cambodia Program, Phnom Penh, Cambodia.

Evans, T.D., Arpels, M. \& Clements, T. (2012) Pilot REDD activities in Cambodia are expected to improve access to forest resource use rights and land tenure for local communities. In Lessons About Land Tenure, Forest Governance and REDD+. Case Studies From Africa, Asia and Latin America (eds L. Naughton-Treves \& C. Day), pp. 73-82. UW-Madison Land Tenure Center, Madison, USA.

Evans, T.D., O'Kelly, H.J., Soriyun, M., Hor, N.M., Phaktra, P., Pheakdey, S. \& Pollard, E. (2013) Seima protection forest. In Evidence-Based Conservation: Lessons From the Lower Mekong (eds T.C.H. Sunderland, J.A. Sayer \& H. Minh-Ha), pp. 157-186. CIFOR, Bogor, Indonesia.
Forestry Administration (2002) Chapter 10-Conservation of Wildlife. Law on Forestry. Articles 48-50. Royal Government of Cambodia, Phnom Penh, Cambodia.

GLYNN, A.N. (2013) What can we learn with statistical truth serum? Design and analysis of the list experiment. Public Opinion Quarterly, 77, 159-172.

Gompper, M.E. (2014) The dog-human-wildlife interface: assessing the scope of the problem. In Free-ranging Dogs and Wildlife Conservation (ed. M.E. Gompper), pp. 9-54. Oxford University Press, Oxford, UK.

Gray, T.N.E., Sokun, H., Lefter, E., Grosu, R., Kimsreng, K., Omaliss, K. \& Gauntlett, S. (2016) A decade of zero elephant poaching in the Cardamom Rainforest Landscape, Cambodia. Gajah, 45, 35-38.

Gray, T.N.E., Hughes, A.C., Laurance, W.F., Long, B., Lynam, A. J., Kelly, H.O. et al. (2017) The wildlife snaring crisis: an insidious and pervasive threat to biodiversity in Southeast Asia. Biodiversity and Conservation, 27, 1031-1037.

Griffin, O. (2019) The Biodiversity of Keo Seima Wildlife Sanctuary

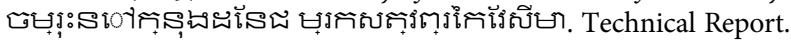
Wildlife Conservation Society, Phnom Penh, Cambodia. dx.doi.org/ 10.13140/RG.2.2.23315.8400o [accessed 17 March 2020].

HARrison, R.D. (2011) Emptying the forest: hunting and the extirpation of wildlife from tropical nature reserves. Bioscience, 61, 919-924.

Harrison, R.D., Sreekar, R., Brodie, J.F., Brook, S., Luskin, M., KeLLy, H.O. et al. (2016) Impacts of hunting on tropical forests in Southeast Asia. Conservation Biology, 30, 972-981.

Heng, S., Dong, T., Hon, N. \& Olsson, A. (2016) The hairy-nosed otter Lutra sumatrana in Cambodia: distribution and notes on ecology and conservation. Cambodian Journal of Natural History, 2, 102-110.

Hinsley, A., Nuno, A., Keane, A., St John, F.A.V. \& Ibbett, H. (2019) Asking sensitive questions using the unmatched count technique: applications and guidelines for conservation. Methods in Ecology and Evolution, 10, 308-319.

Hughes, A.C. (2017) Understanding the drivers of Southeast Asian biodiversity loss. Ecosphere, 8, eo1624.

Iвветt, H. \& Brittain, S. (2019) Conservation publications and their provisions to protect research participants. Conservation Biology, $34,80-92$.

Ibbett, H., Milner-Gulland, E.J., Beale, C., Dobson, A.D., Griffin, O., O’Kelly, H. \& Keane, A. (2020) Experimentally assessing the effect of search effort on snare detectability. Biological Conservation, 247, 108581.

Ingram, D.J., Coad, L., Abernethy, K., Maisels, F., Stokes, E.J., Вово, K.S. et al. (2017) Assessing Africa-wide pangolin exploitation by scaling local data. Conservation Letters, 11, e12389.

Jones, S., Keane, A., St John, F.A.V., Vickery, J. \& Papworth, S. (2019) Audience segmentation to improve targeting of conservation interventions for hunters. Conservation Biology, 33, 895-905.

Keane, A., Jones, J.P.G. \& Milner-Gulland, E.J. (2011) Encounter data in resource management and ecology: pitfalls and possibilities. Journal of Applied Ecology, 48, 1164-1173.

KRUMPAL, I. (2013) Determinants of social desirability bias in sensitive surveys: a literature review. Quality and Quantity, 47, 2025-2047.

Loucks, C., Mascia, M.B., Maxwell, A., Huy, K., Duong, K., Chea, N. et al. (2009) Wildlife decline in Cambodia, 1953-2005: exploring the legacy of armed conflict. Conservation Letters, 2, 82-92.

Loveridge, R., Cusack, J., Eames, J., Samnang, E. \& Willcox, D. (2018) Mammal records and conservation threats in Siem Pang wildlife sanctuary and Siem Pang Khang Lech wildlife sanctuary, Cambodia. Cambodian Journal of Natural History, 2, 76-89. 
Mahanty, S. \& Milne, S. (2016) Anatomy of a boom: cassava as a 'gateway' crop in Cambodia's north eastern borderland. Asia Pacific Viewpoint, 57, 180-193.

Martin, E.B. \& Phipps, M. (1996) A review of the wild animal trade in Cambodia. TRAFFIC Bulletin, 16, 45-6o.

Milner-Gulland, E.J., Bennett, E.L., Abernethy, K., Bakarr, M., Bennett, E., Bodmer, R. et al. (2003) Wild meat: the bigger picture. Trends in Ecology and Evolution, 18, 351-357.

MoE (Ministry of Environment) (2008) Chapter 8. Article 41. Protected Areas Law. Phnom Penh, Cambodia.

MoE (Ministry of Environment) (2016) Sub-Decree No.83 on Establishment of Keo Seima Wildlife Sanctuary. Phnom Penh, Cambodia.

Nielsen, M.R., Meilby, H., Smith-Hall, C., Pouliot, M. \& Treue, T. (2018) The importance of wild meat in the global south. Ecological Economics, 146, 696-705.

Noss, A.J. (1998) The impacts of cable snare hunting on wildlife populations in the forests of the Central African Republic. Conservation Biology, 12, 390-398.

Nuno, A. \& S T John, F.A.V. (2015) How to ask sensitive questions in conservation: a review of specialized questioning techniques. Biological Conservation, 189, 5-15.

O’Kelly, H.J., Evans, T.D., Stokes, E.J., Clements, T., Dara, A., GAtely, M. et al. (2012) Identifying conservation successes, failures and future opportunities; assessing recovery potential of wild ungulates and tigers in Eastern Cambodia. PLOS ONE, 7, e4048.

O’Kelly, H.J., Rowcliffe, M.J., Durant, S.M. \& MilnerGulland, E.J. (2018) Robust estimation of snare prevalence within a tropical forest context using N-mixture models. Biological Conservation, 217, 75-82.

R Core TEAm (2017) R: a Language and Environment for Statistical Computing. R Foundation for Statistical Computing, Vienna, Austria. r-project.org [accessed 17 March 2020].

Riggs, R.A., LAngston, J.D. \& SAyER, J. (2018) Incorporating governance into forest transition frameworks to understand and influence Cambodia's forest landscapes. Forest Policy and Economics, 96, 19-27.

Ripple, W.J., Abernethy, K., Betts, M.G., Chapron, G., Dirzo, R., Galetti, M. et al. (2016) Bushmeat hunting and extinction risk to the world's mammals. Royal Society Open Science, 3, 160498.

Rostro-García, S., Kamler, J.F., Ash, E., Clements, G.R., Gibson, L., Lynam, A.J. et al. (2016) Endangered leopards: range collapse of the Indochinese leopard (Panthera pardus delacouri) in Southeast Asia. Biological Conservation, 201, 293-300.

Sodri, N.S., Koh, L.P., Brook, B.W. \& NG, P.K.L. (2004) Southeast Asian biodiversity: an impending disaster. Trends in Ecology and Evolution, 19, 654-66o.

Solomon, J., Jacobson, S.K., Wald, K.D. \& Gavin, M. (2007) Estimating illegal resource use at a Ugandan Park with the randomized response technique. Human Dimensions of Wildlife, $12,75-88$.

Souter, N.J., Simpson, V., Mould, A., Eames, J.C., Gray, T.N.E., SINCLAIR, R. et al. (2016) Editorial: will the recent changes in protected area management and the creation of five new protected areas improve biodiversity conservation in Cambodia? Cambodian Journal of Natural History, 2016, 1-5.

St John, F.A.V., Keane, A.M. \& Milner-Gulland, E.J. (2013) Effective conservation depends upon understanding human behaviour. In Key Topics in Conservation Biology 2 (eds D.W. Macdonald \& K.J. Willis), pp. 344-361. 1st edition. John Wiley \& Sons, Oxford, UK.

Starr, C., Nekaris, K.A.I.A.I., Streicher, U. \& Leung, L.K.-P.P. (2011) Field surveys of the Vulnerable pygmy slow loris Nycticebus pygmaeus using local knowledge in Mondulkiri Province, Cambodia. Oryx, 45, 135-142.

Tourangeau, R. \& Yan, T. (2007) Sensitive questions in surveys. Psychological Bulletin, 133, 859-883.

Travers, H. (2014) Making friends with benefits: an investigation into the use of incentives for the conservation of forest commons. $\mathrm{PhD}$ thesis, Imperial College London, London, UK.

Travers, H., Winney, K., Clements, T., Evans, T. \& Milner-Gulland, E.J. (2015) A tale of two villages: an investigation of conservation-driven land tenure reform in a Cambodian Protection Forest. Land Use Policy, 43, 186-196.

Travers, H., Clements, T. \& Milner-Gulland, E.J. (2016) Predicting responses to conservation interventions through scenarios: a Cambodian case study. Biological Conservation, 204, 403-410.

Veríssimo, D. \& WAn, A.K.Y. (2019) Characterizing efforts to reduce consumer demand for wildlife products. Conservation Biology, $33,623-633$.

Yersin, H., Asimme, C., Voordouw, M.J. \& Zuberbühler, K. (2017) Impact of snare injuries on parasite prevalence in wild chimpanzees (Pan troglodytes). International Journal of Primatology, 38, 21-30. 